\title{
Penerapan Siklus Promosi Kesehatan Untuk Meningkatkan Phbs Dan Kadarzi Di Rw 40, Dusun Jaranan, Desa Banguntapan, Kecamatan Banguntapan, Kabupaten Bantul
}

\author{
${ }^{1)}$ Marsiana Wibowo ${ }^{*}$ (2) Nurmala Apriyanti, ${ }^{3)}$ Nur Syamsiah Awuni, ${ }^{4)}$ Alda Triana, \\ ${ }^{5}$ Meicy Devisca, ${ }^{6}$ Fini Khafillah, ${ }^{7)}$ Berlian Febri Utami \\ ${ }^{122) 3445) 6(7)}$ Program Studi Kesehatan Masyarakat, Fakultas Kesehatan Masyarakat \\ Universitas Ahmad Dahlan \\ Alamat: Jalan Prof. Dr. Soepomo, SH., Janturan, Warungboto, Umbulharjo Yogyakarta 55164 \\ *Email : marsiana.wibowo@ikm.uad.ac.id
}

\begin{abstract}
ABSTRAK
Program promotif gaya hidup sehat telah banyak digencarkan pemerintah diantaranya Perilaku Hidup Bersih dan Sehat (PHBS) serta Keluarga Sadar Gizi (Kadarzi). Namun demikian, cakupan penerapan indikatornya seringkali tidak dapat terpenuhi, hanya beberapa atau sebagian keluarga yang menerapkan secara utuh. Dusun Jaranan menjadi salah satu yang belum menerapkan secara utuh. Data terakhir menunjukkan 53,35\% untuk PHBS tahun 2018 sedangkan kadarzi sudah 95,44\%. Penerapan ini selalu mengalami perubahan naik maupun turun. Oleh karena itu diperlukan penilaian kesehatan dan upaya promotif yang berkesinambungan. Studi ini bertujuan untuk melakukan seluruh tahapan siklus promosi kesehatan di RW 40 Dusun Jaranan. Metodenya penilaian kesehatan menggunakan metode kuantitatif dengan survey. Data yang dihasilkan berupa permasalahan yang prioritas yaitu masih adanya yang merokok di dalam rumah. Oleh karena itu, program yang disepakati bersama masyarakat adalah peningkatan pengetahuan tentang bahaya rook bagi perokok aktif dan pasif dengan metode ceramah dan alat bantu berupa poster, leaflet, dan video. Intervensi ini dapat berjalan sesuai rencana dan memberikan dampak berupa peningkatan pengetahuan sasaran. Upaya ini harus terus ditindaklanjuti oleh puskesmas setempat agar tidak berhenti pada peningkatan pengetahuan saja, namun juga sikap dan perilaku.
\end{abstract}

Kata Kunci : prioritas masalah kesehatan, intervensi, rokok

\section{ABSTRACT}

The healthy lifestyle promotion program has been intensified by the government including Clean and Healthy Behavior (PHBS) and Nutrition Conscious Families (Kadarzi). However, the scope of the application of the indicators can often not be fulfilled, only a few or some families who apply in full. Jaranan Hamlet is one that has not been implemented in full. The latest data shows 53.35\% for PHBS in 2018 while the levels of have been 95.44\%. This application always changes up and down. Therefore it is necessary to have an ongoing health assessment and promotive effort. This study aims to conduct all stages of the health promotion cycle in RW 40 of Jaranan Hamlet. The method of health assessment uses quantitative methods with surveys. The data generated in the form of a priority problem that is still the existence of smoking in the house. Therefore, the program agreed with the community is to increase knowledge about the dangers of rooks for active and passive smokers with lecture methods and assistive devices in the form of posters, leaflets, and videos. This intervention can go according to plan and have the effect of increasing target knowledge. This effort must continue to be followed up by local health centres so as not to stop at increasing knowledge, but also attitudes and behavior.

Keyword : priority health problem, intervention, cigarettes. 
Volume. 1 No. 2 tahun 2020

Nov 2020 - Mei 2021
ISSN (online): 2722-2055 https://jurnal.umj.ac.id/index.php/ASSYIFA
AS-SYIFA: Jurnal Pengabdian dan Pemberdayaan Kesehatan Masyarakat

\section{PENDAHULUAN}

Mencegah lebih baik daripada mengobati. Slogan yan diadopsi direktorat promosi kesehatan dan pemberdayaan masyarakat sebagai salah satu merchandise media promosi kesehatan ini sungguh sesuai dengan prinsip kesehatan masyarakat, bahwa kita harus selalu melakukan pencegahan untuk memelihara kesehatan masyarakat, karena ketika seseorang jatuh sakit maka akan banyak sumber daya yang harus dikeluarkan (Direktorat Promosi Kesehatan dan Pemberdayaan Masyarakat Kementerian Kesehatan RI, 2018). Oleh karena itu, pemerintah terus menyerukan gerakan-gerakan hidup sehat dan melakukan pengukuran dampak kampanye tersebut. Perilaku Hidup Bersih dan Sehat (PHBS), Keluarga Sadar Gizi (Kadarzi), serta revitalisasi Posyandu terus digalakkan. Pemerintah melalui Puskesmas terus melaksanakan fungsi Upaya Kesehatan Masyarakat (UKM) di wilayah-wilayah kerjanya. Berdasarkan laporan Dinas Kesehatan, keluarga ber-PHBS di Kabupaten Bantul sebesar 47,14\% pada tahun 2017 (Dinas Kesehatan Kabupaten Bantul, 2018).

Dusun Jaranan, Desa Banguntapan, Kecamatan Banguntapan, DI. Yogyakarta adalah salah satu Dusun yang terus mendapatkan pendampingan dan pemantauan tentang PHBS, Kadarzi, dan Posyandu oleh pemerintah melalui Puskemas Banguntapan III. Cakupan berPHBS di Dusun ini sangat dinamis. Enam tahun terakhir dari 2013 - 2018 cakupan secara berurutan adalah $51,8 \%, 45,9 \%, 39,3 \%, 41,4 \%, 70,59 \%, 53,35 \%$. Penurunan yang cukup siknifikan dari tahun 2017 ke 2018. Dusun ini dibawah wilayah kerja Puskesmas Banguntapan III. Berdasarkan data dari Puskemas Banguntapan III pula, keluarga yang telah berKadarzi sebanyak 95,44\% (Puskemas Banguntapan 3, 2018). Latar belakang cakupan berPHBS di Dusun tersebut yang tidak terus meningkat namun naik dan turun harus dicari tahu. Akar masalah harus ditelusuri.

Data tersebut menjelaskan bahwa perilaku sehat masyarakat harus terus dipantau dan didampingi agar terus diterapkan hingga masyarakat berdaya. Oleh karena itu, perlu dilakukan upaya dari community diagnosis hingga evaluasi yang berkesinambungan. Hasil proses tersebut harus dilaporkan ke pihak-pihak yang berwenang dan disosialisasikan ke masyarakat agar masyarakat memiliki kesadaran yang konsisten untuk hidup sehat. Tujuan dari kegiatan pengabdian ini adalah menentukan menerapkan siklus promosi kesehatan untuk meningkatkan PHBS dan Kadarzi yang meliputi tahapan analisis dan diagnosis komunitas, penilaian target, pengembangan program, implementasi, dan evaluasi di RW 40 Dusun Jaranan, Desa Banguntapan, Kecamatan Banguntapan, Kabupaten Bantul, DI. Yogyakarta.

\section{METODE}

Metode pelaksanaan kegiatan pengabdian kepada masyarakat untuk menyelesaikan permasalahan di RW 40 Dusun Jaranan terdiri dari beberapa tahap, yaitu:

\section{Analisis dan diagnosis komunitas}

Analisis dan diagnosis komunitas adalah proses investigasi sumber daya dan kebutuhan yang ada di masyarakat. Pada tahap ini akan dikumpulkan data tentang kesehatan yang ada di RW 40 Dusun Jaranan. Data yang dikumpulkan berupa data data demografi, PHBS, Kadarzi,dan administrasi Posyandu yang dilakukan melalui survey. Pelaksana bekerja sama dengan Puskemas Baguntapan III dalam melaksanakan survey. Instrument survey telah disiapkan oleh Puskesmas Banguntapan III.

1. Data demografi: jumlah Kepala Keluarga (KK), data stakeholder, data kader kesehatan.

2. Data keluarga ber-PHBS 
Data keluarga ber-PHBS dikumpulkan secara langsung (data primer) oleh pelaksana pengabdian kepada masyarakat. Metode pengumpulannya adalah sebagai berikut:

1. Metode: kuantitatif

2. Populasi: KK di RW 40 yang berjumlah 199 KK (RT 7: 55 KK, RT 8: 58 KK, RT 9: 86 KK)

3. Sampel: penghitungan sampel menggunakan rumus Lemeshow dengan pemaparan sebagai berikut (Lemeshow et al., 1990):

$$
\begin{aligned}
& P=0,5 \\
& d=5 \% \\
& Q=1-0,5 \Rightarrow 0,5
\end{aligned}
$$

$$
\begin{aligned}
n & =\frac{Z \alpha^{2} \cdot P \cdot Q \cdot N}{d^{2} \cdot(n-1)+Z \alpha^{2} \cdot P Q} \\
& =\frac{(1,96)^{2} \cdot 0,5 \cdot 0,5 \cdot 199}{(0,05)^{2} \cdot 1,98+(1,96)^{2} \cdot 0,5 \cdot 0,5} \\
& =\frac{3,8416 \cdot 0,25 \cdot 199}{0,495+0,96} \\
& =\frac{191,04}{1,455} \\
=131,29 & \sim 132 \mathrm{KK}
\end{aligned}
$$

Penghitungan tersebut menghasilkan jumlah sampel minimal adalah 132 KK. Sebagai antisipasi data yang tidak lengkap, jumlah sampel ditambah $10 \%$, sehingga jumlah sampel adalah $145 \mathrm{KK}$. Pembagian besar sampel tiap RT secara proporsi sebagai berikut:

Tabel 1. Sampel per RT

\begin{tabular}{|l|l|l|ll|}
\hline RT & Jumlah KK & Populasi (KK) & \multicolumn{2}{|c|}{$\begin{array}{c}\text { Sampel per RT } \\
(\mathrm{KK})\end{array}$} \\
\hline 7 & 55 & 199 & $55 / 199 \times 145$ & $=40$ \\
\hline 8 & 58 & 199 & $58 / 199 \times 145$ & $=42$ \\
\hline 9 & 86 & 199 & $86 / 199 \times 145$ & $=63$ \\
\hline & & & Total & $=145$ \\
\hline
\end{tabular}

4. Instrumen

Instrumen pengukuran PHBS menggunakan kuesioner dengan 10 indikator PHBS, yaitu:

a. Persalinan ditolong oleh tenaga kesehatan

b. Memberi bayi ASI ekskusif

c. Menimbang bayi dan balita setiap bulan

d. Menggunakan air bersih

e. Mencuci tangan dengan air bersih yang mengalir dan sabun

f. Menggunakan jamban sehat

g. Memberantas jentik di rumah

h. Melakukan aktivitas fisik setiap hari

i. Makan sayur dan buah setiap hari

j. Tidak merokok di dalam rumah

Setiap indikator terdiri dari 2 pilihan jawaban, yaitu Ya (skor 1) dan Tidak (Skor 0). Untuk indikator pertama, kedua, dan ketiga jika tidak ada sasarannya, maka jawaban ditulis dengan angka 2. Keluarga berPHBS jika semua indikator terpenuhi. Jika ada salah 
satu indikator yang tidak terpenuhi, maka keluarga tersebut masuk ke kategori tidak berPHBS.

5. Teknik pengambilan sampel : simple random sampling

Data berKadarzi

1. Metode: kuantitatif

2. Populasi: KK di RW 40 yang berjumlah 199 KK (RT 7: 55 KK, RT 8: 58 KK, RT 9: 86 KK)

3. Sampel: penghitungan sampel menggunakan rumus Lemeshow dengan pemaparan sebagai berikut (Lemeshow et al., 1990):

$$
\begin{aligned}
& \begin{array}{l}
\mathrm{P}=0,5 \\
\mathrm{~d}=5 \% \\
\mathrm{Q}=1-0,5=>0,5
\end{array} \\
& n=\frac{\mathrm{Z} \alpha^{2} \cdot P \cdot Q \cdot N}{d^{2} \cdot(n-1)+Z \alpha^{2} \cdot P Q} \\
& =\frac{(1,96)^{2} \cdot 0,5 \cdot 0,5 \cdot 199}{(0,05)^{2} \cdot 1,98+(1,96)^{2} \cdot 0,5 \cdot 0,5} \\
& =\frac{3,8416 \cdot 0,25 \cdot 199}{0,495+0,96} \\
& =\frac{191,04}{1,455} \\
& =131,29
\end{aligned}
$$

Penghitungan tersebut menghasilkan jumlah sampel minimal adalah 132 KK. Sebagai antisipasi data yang tidak lengkap, jumlah sampel ditambah $10 \%$, sehingga jumlah sampel adalah $145 \mathrm{KK}$. Pembagian besar sampel tiap RT secara proporsi sebagai berikut:

Tabel 2. Sampel per RT

\begin{tabular}{|l|l|l|ll|}
\hline RT & $\begin{array}{c}\text { Jumlah } \\
\text { KK }\end{array}$ & $\begin{array}{c}\text { Populasi } \\
(\mathrm{KK})\end{array}$ & $\begin{array}{c}\text { Sampel per RT } \\
(\mathrm{KK})\end{array}$ & \\
\hline 7 & 55 & 199 & $55 / 199 * 145$ & $=40$ \\
\hline 8 & 58 & 199 & $58 / 199 * 145$ & $=42$ \\
\hline 9 & 86 & 199 & $86 / 199 * 145$ & $=63$ \\
\hline & & & Total & $=145$ \\
\hline
\end{tabular}

4. Instrumen

Instrumen pengukuran Kadarzi menggunakan kuesioner dengan 6 indikator Kadarzi yaitu:
a. Menimbang berat badan secara teratur
b. Memberikan ASI Eklusif (ASI)
c. Makan beraneka ragam
d. Menggunakan Garam beryodium
e. Mengkonsumsi Suplemen Gizi
f. Sarapan Pagi

Setiap indikator terdiri dari 2 pilihan jawaban, yaitu Ya (skor 1) dan Tidak (Skor 0). Untuk indikator pertama, kedua, dan ketiga jika tidak ada sasarannya, maka jawaban ditulis dengan angka 2. Keluarga berKadarzi jika semua indikator terpenuhi. Jika ada salah satu indikator yang tidak terpenuhi, maka keluarga tersebut masuk ke kategori tidak berKadarzi.

5. Teknik pengambilan sampel : simple random sampling 
AS-SYIFA: Jurnal Pengabdian dan Pemberdayaan Kesehatan Masyarakat

Data administrasi posyandu

a. Metode: kualitatif

b. Subjek: kader posyandu

c. Teknik pengambilan data: Dokumen dan observasi

Penilaian Target

Pada tahap ini akan ditentukan fokus dari program. Hasil dari community analysis and diagnosis, akan ditemukan beberapa permasalahan kesehatan. beberapa permasalahan kesehatan tersebut akan dipilih prioritas masalah dan dicari akar masalah. Setelah itu pelaksana program berserta stakeholder bekerja sama untuk menentukan program yang tepat. Proses ini difasilitasi dalam kegiatan yang disebut Musyawarah Masyarakat Desa (MMD).

\section{Pengembangan Program}

\section{Implementasi}

Pengembangan program didiskusikan bersama-sama stakeholder pada MMD.

Pada saat ini, program yang telah direncanakan diimplementasikan.

\section{Evaluasi}

Pada tahap ini, program yang telah dilaksanakan akan dievaluasi. Evaluasi dilakukan dengan 2 tipe, yaitu evaluasi proses dan dampak.

\section{HASIL DAN PEMBAHASAN}

Hasil

Analisis dan Diagnosis Komunitas

Hasil community analysis and diagnosis di RW 40 menunjukkan bahwa terdapat beberapa permasalahan kesehatan. Hasil survey per indikator PHBS dan Kadarzi ditunjukkan pada Gambar 1 dan 2.

Persentase Keluarga Menerapkan PHBS per Indikator di RW 40 Dusun Jaranan, Desa Banguntapan, Kecamatan Banguntapan, Kabupaten Bantul, Tahun 2020

10. Tidak merokok di dalam rumah

9. Makan sayur dan buah setiap hari

8. Melakukan aktivitas fisik setiap hari

7. Memberantas jentik di rumah

6. Menggunakan jamban sehat

5. Mencuci tangan dengan air bersih yang

4. Menggunakan air bersih

3. Menimbang bayi dan balita setiap bulan

2. Memberi bayi ASI ekskusif

1. Persalinan ditolong oleh tenaga kesehatan

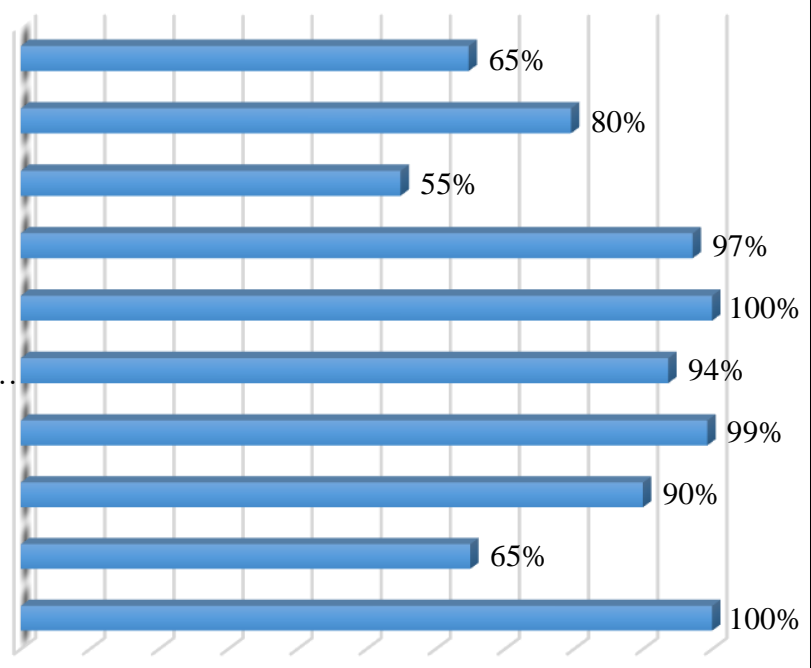

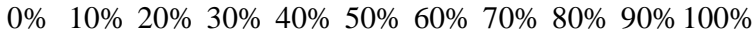

- Menerapakan 
Volume. 1 No. 2 tahun 2020 Nov 2020 - Mei 2021
ISSN (online): 2722-2055 https://jurnal.umj.ac.id/index.php/AS-

SYIFA

AS-SYIFA: Jurnal Pengabdian dan Pemberdayaan Kesehatan Masyarakat

Gambar 1. Persentase Keluarga Menerapkan PHBS per Indikator di RW 40 Dusun Jaranan, Desa Banguntapan, Kecamatan Banguntapan, Kabupaten Bantul, Tahun 2020.

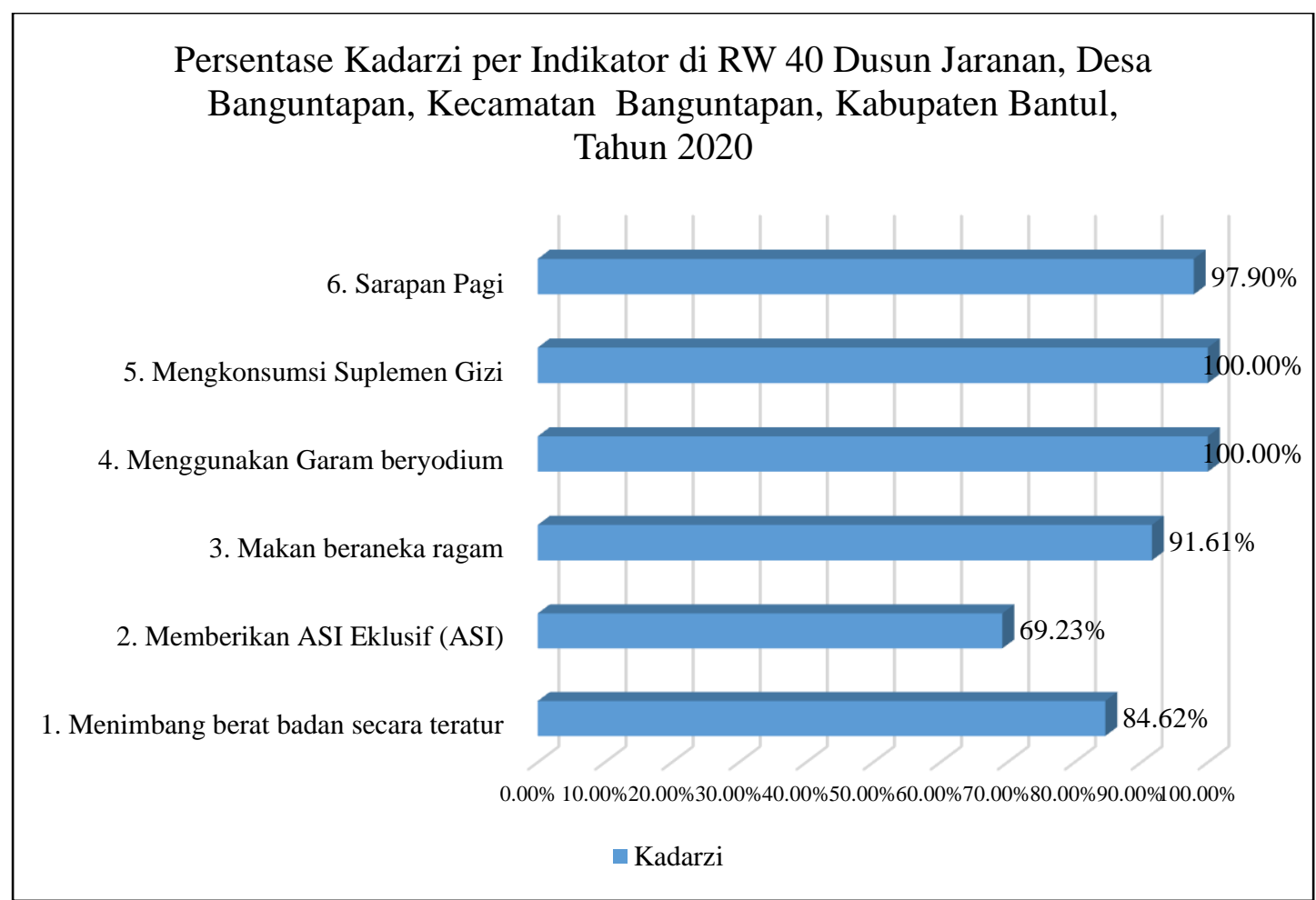

Gambar 2. Persentase Kadarzi per Indikator di RW 40 Dusun Jaranan, Desa Banguntapan, Kecamatan Banguntapan, Kabupaten Bantul, Tahun 2020

Hasil survey terhadap pengisian administrasi posyandu diketahui bawah dari 14 buku Posyandu yang harus ada, hanya 11 buku posyandu yang ada. Tiga buku tersebut adalah Data jumlah pengunjung/petugas posyandu/data bayi lahir atau meninggar, Buku daftar kegiatan posyandu, dan Buku catatan kegiatan posyandu. Selain temuan tersebut, terdapat dua buku yang tidak terisi dengan lengkap, yaitu buku kas dan buku imunisasi.

\section{Penilaian Target}

Hasil community analysis and diagnosis menghasilkan beberapa permasalahan kesehatan. Permasalahan utama dari PHBS dan Kadarzi adalah (1) kurangnya aktifitas fisik (45\%) (2) masih adanya yang merokok di dalam rumah (35\%) (3) rendahnya makan buah dan sayur (20\%) (4) rendahnya makan beraneka ragam (8,39\%) (4) rendahnya cakupan ASI ekslusif $(40,77 \%)$. Data dari pengisian 14 buku posyandu diketahui bahwa masih belum lengkapnya isian beberapa buku. Hasil tersebut dimusyawarahkan dalam Musyawarah Masyarakat Desa (MMD). Berdasarkan kesepakatan, permasalan ASI eksklusif dan administrasi posyandu akan diselesaikan oleh kader dibantu oleh tim pengabdian, sedangkan tiga yang lain akan dipilih salah satu sebagai prioritas masalah. Prioritas masalah dipilih menggunakan metode delbecq, yaitu masing-masing peserta menuliskan rangking urutan permasalahan dari yang paling prioritas. Berdasarkan diskusi, permasalahan priorias yang didapatkan adalah masih adanya yang merokok di dalam rumah.

Pengembangan Program 
Pengembangan program dilakukan dengan memperhatikan sumber daya dan hambatan yang ada di masyarakat. Warga bersepakat untuk memberikan intervensi berupa pemasangan poster di wilayah yang mudah diakses masyarakat untuk meningkatkan pengetahuan warga. Saat kegiatan ini berlangsung, warga memiliki keterbatasan waktu dalam pelaksanaan program, sehingga pelaksana memanfaatkan ketersediaan pertemuan warga yang akan berlangsung selain pemasangan poster. Tujuan intervensi adalah untuk meningkatkan pengetahuan warga tentang bahanya rokok pada perokok aktif dan pasif. Metode intervensi dengan edukasi kesehatan berupa ceramah dan penggunan media berupa poster, leaflet, dan video. Materi intervensi adalah bahanya merokok bagi perokok aktif dan pasif, kandungan rokok, serta testimoni mantan perokok aktif, testimoni perokok aktif yang menderita penyakit, serta motivasi dari dokter. Aktivitas intervensi berupa ceramah di arisan ibu-ibu di RW 40 didukung media poster, leaflet, dan video. Pemateri intervensi adalah mahasiswa kesehatan masyarakat dan farmasi dengan pendampingan Dosen sebagai ketua pengabdian.

Implementasi

Berdasarkan perencanaan dalam pengembangan program, intervensi dilaksanakan pada tanggal 20 Februari 2020 di rumah seorang warga, dengan sasaran ibu-ibu berjumlah 20 orang.

\section{Evaluasi}

Berdasarkan proses intervensi yang sudah berjalan, unsur-unsur program telah berjalan sesuai dengan perencanaan. Unsur-unsur tersebut meliputi waktu, materi, pemateri, sasaran, dan media yang digunakan. Dampak yang dihasilkan dari kegiatan intervensi menghasilkan peningkatan pengetahuan sasaran tentang bahaya merokok. Hasil analisis menunjukkan skor rata-rata pengetahuan sebelum intervensi adalah 44,5 sedangkan setelah intervensi adalah 73 . Data tersebut menunjukkan ada peningkatan skor rata-rata pengetahuan tentang bahaya rokok sebesar 28,5.

\section{Pembahasan}

Kegiatan ini menghasilkan beberapa data dari masyarakat, yaitu melalui beberapa tahap siklus promosi kesehatan, yaitu community analysis and diagnosis, targeted assessment, program development, implementation, dan evaluation. Community analysis and diagnosis sering disebut juga sebagai needs assessment. Community analysisand diagnosis akan menyediakan data sumber daya, kebutuhan kesehatan, dan permasalahan kesehatan yang ada di masyarakat (Dignan and Carr, 1992). Pada tahap ini, pelaksana pengabdian telah mampu menyajikan permasalahan kesehatan terkait PHBS, Kadarzi, dan pengisian 14 buku Posyandu. Ketiga topik masalah tersebut difokuskan oleh pengabdi berdasarkan informasi dari puskesmas setempat. Hal ini berarti pengabdi telah menjalin kerja sama yang baik dengan pelayanan kesehatan setempat dalam mengeksplorasi permasalahan kesehatan yang dialami suatu komunitas. Community analysis telah digunakan dan menghasilkan data dengan baik sebagai basis bukti merencanakan program promosi kesehatan (Reece, 1998; Richmond et al., 2020).

Hasil survey pada tahap community analysis and diagnosis menghasilkan empat masalah utama untuk ditentukan prioritas masalah. Empat masalah tersebut adalah rendahnya perilaku merokok di dalam rumah, kurangnya makan buah dan sayur, kurangnya makan beraneka ragam, dan kurangnya aktifitas fisik masyarakat RW 40. Prioritas masalah dari keempat tersebut adalah rendahnya perilaku merokok di dalam rumah, maksudnya perilaku merokok di dalam rumah bagi perokok masih tinggi. Pemilihan prioritas masalah menggunakan 
metode delbecq. Metode ini telah digunakan di banyak kegiatan dalam menentukan prioritas masalah karena mudah dalam penggunaannya (Pujiati, 2018; Syaiful, Supriatna and Apriana, 2019; Tyas, 2020).

Penentuan intervensi harus dilakukan berdasarkan kesepakatan dengan warga setempat. Penyuluhan dan pemasangan poster adalah kesepakatan untuk mengatasi kurangnya kesadaran untuk tidak merokok di dalam rumah. Partisipasi dalam MMD untuk menentukan prioritas masalah pada kegiatan ini termasuk rendah karena stakeholder yang hadir hanya sedikit, yaitu 6 orang. Hanya ada 1 perwakilan ketua RT yang hadir, sedangkan seharusnya 3. Sedangkan yang lain adalah Ketua Dusun dan Kader kesehatan. Kelemahan dari kegiatan ini adalah tidak melibatkan masyarakat umum dikarenakan keterbatasa waktu dan tempat untuk mengadakan MMD di RW 40. Namun demikian, hasil suara ini sudah diakui oleh warga untuk mewakili suara warga. Partisipasi warga untuk MMD dipengaruhi oleh pendapatan, status sosial, budaya musyawarah. Faktor yang paling berpengaruh adalah kejelasan informasi tentang musyawarah masyarakat desa (Heryanti et al., 2011). RW 40 Dusun Jaranan terletak di kabupaten Bantul, namun tidak bisa dikatakan sebagai pedesaan, namun sudah termasuk kategori perkotaan. Budaya musyawarah di perkotaan masih terus ada, namun dimungkinkan kejelasan informasi tentang MMD ini yang belum jelas sehingga terdapat peserta MMD yang tidak hadir.

Edukasi yang dikembangkan diputuskan untuk meningkatkan pengetahuan warga tentang bahaya merokok bagi perokok aktif dan pasif. Diperlukan suatu intervensi terarah terutama di wilayah dengan prevalensi paparan asap rokok tinggi, menargetkan kelompok masyarakat pendidikan rendah, miskin, memiliki balita, kerja sektor informal dan tinggal di wilayah perdesaan di Indonesia (Herawati, Afriandi and Wahyudi, 2019). Keterbatasan ketersediaan waktu di lapangan menjadikan sasaran yang diambil untuk penyuluhan adalah ibu-ibu di arisan RW 40 dengan jumlah 20 orang. Harapan mengusung program, ibu-ibu sebagai orang yang berpengaruh bagi keluarganya dapat mengedukasi anggota keluarga yang merokok untuk tidak merokok di dalam rumah. Ibu-obu juga merupakan perokok pasif yang dapat menerima dampak buruk untuk kesehatannya akibat orang lain yang merokok. Ibu-ibu dapat memberikan teguran dan tidak mendukung perilaku suaminya yang merokok (Mahardika, Luthviatin and Nafkadini, 2017). Anak-anak bisa mengalami batuk dan sesak jika orang tua merokok di dalam rumah (Ramdani, Wahyudin and Nursela, 2018). Selain itu, perilaku orang tua bisa menjadi contoh bagi anaknya. Terdapat hubungan antara peran orang tua dan saudara dengan perilaku merokok remaja (Isa, Lestari and Afa, 2017; Wibowo et al., 2019).

Berdasarkan informasi dalam MMD, salah satu faktor yang menyebabkan anggota masyarakat merokok adalah anggapan bahwa merokok dapat menghilangkan stress dan membuat lebih relaks. Faktor intrinsik ini menjadi asumsi yang salah yang harus dibenarkan. Faktor intrinsik memiliki pengaruh yang lebih besar dibandingkan faktor ekstrinsik. Faktor intrinsik seperti usia, jenis kelamin, kepribadian, stress (Tristanti, 2016).

Berdasarkan evaluasi proses yang dilakukan, intervensi yang direncanakan telah berjalan sesuai rencana. Evaluasi dampak juga telah dilaksanakan dan hasilnya sesuai harapan, yaitu meningkatnya pengetahuan ibu-ibu tentang bahaya merokok bagi perokok aktif maupun perokok pasif. Pengabdi mengkombinasikan metode ceramah, penyebaran leaflet, poster, dan pemutaran video untuk meningkatkan pengetahuan sasaran. Masing-masing metode memiliki kekuatan sendiri-sendiri sehingga kekuatan yang dimiliki setiap metode mampu meningkatkan pengetahuan sasaran. Leaflet, poster, dan presentasi (ceramah) mampu 
meningkatkan pengetahuan sasaran tentang bahanya merokok (Mohammad, Prabandari and Priyanto, 2012; Akmal, Rahmatika and Fitria, 2015; Iskandar, Ridha and Hernawan, 2015).

\section{KESIMPULAN DAN SARAN}

Berdasarkan serangkaian kegiatan yang telah berlangsung dapat memberikan beberapa dampak pada masyarakat, khususnya masyarakat RW 40, yaitu:

1. Hasil analisis dan diagnosis komunikasi PHBS dan kadarzi menunjukkan masyarakat telah menerapkan indikator-indikator dengan baik. Terdapat indikator yang telah $100 \%$ dilaksanakan, yaitu persalinan ditolong tenaga kesehatan, menggunakan jamban sehat, menggunakan garam beryodium, dan mengkonsumsi suplemen gizi. Namun, ada juga indikator yang belum diterapkan oleh seluruh masyarakat.

2. Hasil penilaian target diketahui beberapa permasalahan kesehatan. Permasalahan utama dari PHBS dan Kadarzi adalah (1) kurangnya aktifitas fisik (45\%) (2) masih adanya yang merokok di dalam rumah (35\%) (3) rendahnya makan buah dan sayur (20\%) (4) rendahnya makan beraneka ragam (8,39\%) (4) rendahnya cakupan ASI ekslusif (40,77\%).

3. Program promosi kesehatan dikembangkan bersama warga berupa dilakukannya penyuluhan dan penyebarluasan poster terkait permasalahan pelaksanaan PHBS dan Kadarzi.

4. Implementasi program telah terlaksana dengan berkerja sama dengan masyarakat berupa penyuluhan dan pemasangan poster.

5. Hasil evaluasi menunjukkan adanya peningkatan pengetahuan tentang penerapan PHBS dan Kadarzi.

6. Sedangkan bagi Puskesmas Banguntapan III, kegiatan ini memberikan dampak yang baik berupa meningkatnya aktifitas warga dalam penilaian kebutuhan serta penanganan permasalahan kesehatan berupa kegiatan promotif di wilayah kerjanya, khususnya di RW 40 Dusun Jaranan. Sedangkan bagi pengabdi, serangkaian ini memberikan dampak yang cukup besar dalam meningkatkan pengalaman dalam berinteraksi dengan masyarakat dan bekerja sama dengan masyarakat dalam menyelesaikan permasalahan kesehatan.

\section{UCAPAN TERIMA KASIH}

Kami mengucapkan terima kasih kepada mitra kami, yaitu Puskemas Banguntapan III serta Fakultas Kesehatan Masyarakat yang mendukung kegiatan pengabdian kepada masyarakat ini.

\section{DAFTAR PUSTAKA}

Akmal, S. Z., Rahmatika, R. and Fitria, N. (2015) 'Program Pemberian Informasi Bahaya Merokok Melalui Leaflet, Presentasi, dan Poster', Prosiding Seminar Nasional Penelitian dan PKM Kesehatan, (2015), pp. 21-28.

Dignan, M. B. and Carr, P. A. (1992) Program Planning for Health Education and Promotion. Second Edi. USA: Lea \& Febiger.

Dinas Kesehatan Kabupaten Bantul (2018) Profil Kesehatan 2018. Bantul.

Direktorat Promosi Kesehatan dan Pemberdayaan Masyarakat Kementerian Kesehatan RI (2018) Merchandise: 2018-Kaos Promkes Mencegah Lebih Baik. Available at: https://promkes.kemkes.go.id/merchandise--2018-kaos-promkes-sehat-mencegah-lebih-baik. 
Herawati, P., Afriandi, I. and Wahyudi, K. (2019) 'Determinan Paparan Asap Rokok di Dalam Rumah: Analisis Data Survei Demografi dan Kesehatan Indonesia (SDKI) 2012', Buletin Penelitia, 47(4), pp. 245-252. Available at: http://ejournal2.litbang.kemkes.go.id/index.php/bpk/article/download/9/1398 (Accessed: 7 April 2020).

Heryanti et al. (2011) 'Faktor-faktor yang Mempengaruhi Partisipasi Masyarakat dalam Musyawarah Desa di Puskesmas Kaligondang Kabupaten Purbalingga', Jurnal Kesmas Indonesia, 4(1), pp. 1-10. Available http://jos.unsoed.ac.id/index.php/kesmasindo/article/view/10/12 (Accessed: 8 April 2020).

Isa, L., Lestari, H. and Afa, J. R. (2017) 'Hubungan Tipe Kepribadian, Peran Orang tua dan Saudara, Peran Teman Sebaya, dan Peran Iklan Rokok dengan Perilaku Merokok pada Siswa SMP Negeri 9 Kediri Tahun 2017', Jurnal Ilmiah Mahasiswa Kesehatan Masyarakat, 2(7), $\mathrm{pp}$

$$
\text { 1-10. Available }
$$
at: http://ojs.uho.ac.id/index.php/JIMKESMAS/article/download/3423/2578.

Iskandar, I., Ridha, A. and Hernawan, A. D. (2015) 'Uji Efektifitas Booklet Berbahasa Daerah dan Metode Ceramah terhadap Pengetahuan Remaja tentang Rokok (Studi di MTs Aswaja Pontianak dan SMP Assalam Pontianak)', JUMANTIK: Jurnal Mahasiswa dan Peneliti Kesehatan, 2(2). doi: 10.29406/JJUM.V2I2.333.

Lemeshow, S. et al. (1990) Besar Sampel dalam Penelitian Kesehatan (Terjemahan oleh drg. Dibyo Pramono, SU, MDSc.). Yogyakarta: Gadjah Mada University Press.

Mahardika, N. H., Luthviatin, N. and Nafkadini, I. (2017) 'Tindakan Ibu Rumah Tangga dalam Penerapan Indikator PHBS Tidak Merokok di dalam Rumah (Studi Kualitatif di Wilayahkerja Puskesmas Pasirian)', e-Jurnal Pustaka Kesehatan, 5(3), pp. 572-579.

Mohammad, F., Prabandari, Y. S. and Priyanto, A. (2012) 'Peningkatan Pengetahuan dan Sikap Terhadap Bahaya Rokok Bagi Kesehatan Melalui Poster Dengan Partisipasi Siswa di Kabupaten Gorontalo', Berita Kedokteran Masyarakat, 28(1), pp. 20-26. Available at: https://pdfs.semanticscholar.org/842d/45fa1e620bd5c637eb1509d5057545adf10f.pdf (Accessed: 8 April 2020).

Pujiati, S. (2018) 'Pemetaan Masalah dan Penentuan Prioritas Program Kesehatan pada Masyarakat Kelurahan Gerem, Kecamatan Grogol, Kota Cilegon', Jurnal Kesehatan Masyarakat: Healrty. LPPM Universitas Ibn Khaldun Bogor, 6(2). doi: 10.32832/hearty.v6i2.1278.

Puskemas Banguntapan 3 (2018) Profil Puskesmas - PUSKESMAS BANGUNTAPAN 3, Puskemas Banguntapan 3 Available at: https://puskesmas.bantulkab.go.id/banguntapan3/profil-puskesmas/ (Accessed: 5 April 2020).

Ramdani, H. T., Wahyudin and Nursela, A. A. (2018) 'Perilaku Orangtua yang Merokok terhadap Kesehatan Anak (0-5 tahun)', Jurnal Keperawatan Aisyiyah, 5(1). Available at: https://journal.stikes-aisyiyahbandung.ac.id/index.php/jka/article/view/77.

Reece, S. M. (1998) 'Community analysis for health planning: strategies for primary care 
practitioners.', The Nurse practitioner, 23(10), pp. 46, 49, 53-6 passim. Available at: http://www.ncbi.nlm.nih.gov/pubmed/9805331 (Accessed: 7 April 2020).

Richmond, S. A. et al. (2020) 'How can we support best practice? A situational assessment of injury prevention practice in public health', BMC Public Health, 20(1), p. 431. doi: 10.1186/s12889-020-08514-x.

Syaiful, Supriatna, A. and Apriana, E. (2019) 'DESA MAJU DUKUNG SDG' s', Jurnal Pengabdian pada Masyarakat: Abdi Dosen, 3(3), pp. 296-300. Available at: http://pkm.uikabogor.ac.id/index.php/ABDIDOS/article/download/340/309.

Tristanti, I. (2016) 'Remaja dan Perilaku Merokok', Prosiding The 3rd University Research Colloqium (URECOL) 2016. LPPM STIKES Muhammadiyah Kudus. Available at: https://publikasiilmiah.ums.ac.id/xmlui/handle/11617/6772 (Accessed: 18 March 2019).

Tyas, R. C. (2020) 'Penentuan Prioritas Masalah Kesehatan Dan Jenis Intervensi Di Rw 13 Dan Rw 14 Kelurahan Ampel Kecamatan Semampir Surabaya Tahun 2018 Penentuan Prioritas Masalah Kesehatan Dan Jenis Intervensi Di Rw 13 Dan Rw 14 Kelurahan Ampel Kecamatan Semampir Surabaya', Jurnal Penelitian Kesehatan, 18(1), pp. 10-13. doi: 10.35882/JPK.V18I1.2.

Wibowo, M. et al. (2019) 'Adolescent smoking behaviour determinants in the city of Yogyakarta , Indonesia', International Journal of Community Medicine and Public Health, 6(12), pp. 5064-5070. doi: http://dx.doi.org/10.18203/2394-6040.ijcmph20195445. 